\title{
Artigo
}

\section{Cruz Report: conteúdo e críticas}

\section{Cruz Report: content and criticisms}

Gustavo C. Macedo ${ }^{1}$

Kaiutan Venerando Ruiz da Silveira ${ }^{2}$

\section{RESUMO}

O trabalho apresenta o contexto em que foi produzido e o conteúdo do relatório "Improving Security of United Nations Peacekeepers", mais conhecido por Cruz Report. Em seguida, identificamos algumas das principais reaçóes da comunidade de especialistas às recomendaçóes deste documento que já é considerado um marco na história das reformas das operaçôes de paz da ONU no século XXI.

Palavras-chave: Cruz Report, operaçóes de paz da ONU, capacetes azuis, reforma da $O N U$

\section{ABSTRACT \\ This work contextualizes and present the main content of the report "Improving Security of United Nations Peacekeepers", also known as Cruz Report. We further identify some of the main reactions from specialists to the recommendations provided by the report, which is already considered to be a watershed in the history of the reforms of the reforms of the UN peacekeeping operations in the $21^{\text {st }}$ century.}

Keywords: Cruz Report, UN peacekeeping operations, blue helmets, UN reform

1. Doutorando em Ciência Política pela Universidade de São Paulo (USP). Coordenador do Grupo de Trabalho em Proteção de Civis da Rede Brasileira de Pesquisa em Operaçóes de Paz (REBRAPAZ). Bolsista da Fundaçáo de Amparo à Pesquisa do Estado de São Paulo (FAPESP). São Paulo, Brasil. ORCID 0000-0002-7771-5464

2. Mestrando em Ciência Política pela Universidade de São Paulo (USP). Bolsista da Coordenação de Aperfeiçoamento de Pessoal de Nível Superior (CAPES). São Paulo, Brasil ORCID 0000-0001-6452-5197 


\section{Introdução}

As operaçóes de paz das Nações Unidas (ONU) estão cada vez mais caras (em relação aos recursos disponíveis), pouco efetivas na realização de suas tarefas de proteção de civis (PoC), e mais perigosas para seus capacetes azuis. Desde 1999, quando as operaçóes passaram a buscar a implementação de proteger civis, o número de mortes de seus soldados cresceu de maneira alarmante. $\mathrm{O}$ fato foi seguido da crescente preocupaçáo por parte dos estados membros - apegados ao princípio tradicional do mínimo uso da força - que queriam evitar mais fatalidades sem aumentar o orçamento das missóes nem abrir mão a execução proativa das tarefas de PoC que, por definição, expóem suas tropas a um risco maior. No contexto desse desafio aparentemente sem respostas, surge o Cruz Report.

A publicação em dezembro de 2017 do relatório "Improving Security of United Nations Peacekeepers" tornou-se peça-chave para entender os recentes debates sobre as reformas das operaçóes de paz da ONU. A encomenda do estudo pelo Secretário-Geral das Naçōes Unidas tinha por objetivo identificar as principais causas do aumento do número de mortes de capacetes-azuis em ação, assim como apresentar recomendaçóes para aumentar a segurança dos soldados sem perder de vista os objetivos das missóes. O projeto foi dividido em duas partes previstos para se encerrar em junho de 2019. A primeira fase consistiu na produçáo do referido relatório e suas recomendações; enquanto a segunda fase tem por objetivo debater tais recomendaçóes com o Conselho de Segurança, a Assembleia Geral, o V Comitê, o Secretariado-Geral, o Departamento de Operações de Paz (DPKO), o Departamento de Apoio de Terreno (DFS), e as agências humanitárias da ONU para, entáo, desenvolver diretrizes específicas para o sistema de concepção, elaboração, implementação, acompanhamento e avaliação das operaçóes de paz. Por fim, o planejamento também prevê considerar as reaçôes dos países contribuidores de tropas (TCCs) e os países contribuidores de policiais (PCCs).

O relatório, que passou a ser chamado de "Cruz Report" (CR) em referência ao seu primeiro autor, o general brasileiro Alberto dos Santos Cruz - o ex-comandante das operaçôes de paz da ONU no Haiti e na República Democrática do Congo -, foi produzido em coautoria com William Phillips - norte-americano, coronel da reversa especialista em avaliação de riscos -, e Salvator Cusimano, especialista em operaçóes de paz na África. O estudo foi a mais recente produçấo encomendada pela ONU desde o relatório do Painel de Alto Nível sobre Operaçóes de Paz (HIPPO) de junho de 2015. Diferentemente de seu antecessor, o CR surge em um contexto contrário às operaçóes de paz, onde os principais países contribuidores de recursos e pessoal dão sinais de esgotamento e exigem uma resposta ao aumento expressivo do número de fatalidades de capacetes azuis em operações de paz.

Logo, o CR insere-se em um contexto de reformas estruturais no pilar de segurança da ONU. Cortes de orçamento, fusão de departamentos, encerramento de missões e revisão dos índices de desempenho são apenas alguns dos indicadores do processo que se iniciou nos últimos cinco anos.

\section{O Cruz Report e suas recomendações}

Para compreender o panorama no qual essas fatalidades estão inseridas, o relatório afirma que de todas as operações de paz em curso atualmente, dois terços são empregadas em áreas complexas e de alto risco (CRUZ; PHILLIPS; CUSIMANO, 2017). As operaçóes que se encaixam dentro dessa caracterização são a MONUSCO (United Nations Stabilization Mission in the Democratic Republic of 
Congo), UNAMID (United Nations/African Union Mission in Darfur), UNMISS (United Nations Mission in the Republic of South Sudan), MINUSMA (Multidimensional Integrated Stabilization Mission in Mali) e a MINUSCA (United Nations Multidimensional Integrated Stabilization Mission in Central African Republic). ${ }^{3}$ Essas operaçōes concentram a maior parte das vítimas por atos de violência no período analisado. Em relação às fatalidades, constatou-se que $90,2 \%$ das mortes são de militares atacados durante comboios e patrulhas no terreno, ou em ataques à própria base ou acampamentos nos quais estavam estacionados (CRUZ; PHILLIPS; CUSIMANO, 2017).

A atuação das Operações de Paz (OPs) em áreas de risco elevado, onde não necessariamente existe uma paz a ser mantida pela ONU, é considerado o fator que diferencia o atual pico de fatalidades pelo qual as OPs estão passando. Diferentemente dos picos anteriores (1960-1962/1992-1996), o CR constata a manutenção de um patamar elevado de fatalidades a partir de 2011, que não sofre decréscimo como nos períodos anteriores, por conta desse novo ambiente de alto risco no qual as OPs estão empregadas (CRUZ; PHILLIPS; CUSIMANO, 2017).

Contudo, a comparação com os picos anteriores é interessante pois revela um novo tipo de postura das Nações Unidas. Segundo o relatório, nos casos anteriores a resposta da ONU foi fechar as OPs que estavam em crise. Por conseguinte, como era de se esperar, observa-se uma queda abrupta no número de fatalidades logo após o fechamento das operações. Contudo, o CR considera improvável a retirada da ONU dos ambientes atuais de conflito nos quais se encontra. Por conta disso, e essa perspectiva é fundamental para se entender o prosseguimento do relatório, o documento defende que as OPs devem se adaptar ao novo tipo de ambiente hostil no qual es-

3. Embora também incorporem outras tarefas, essas operações possuem mandatos explícitos de proteção de civis. tão empregadas e adotar medidas fortes e efetivas no intuito de reduzir as fatalidades (CRUZ; PHILLIPS; CUSIMANO, 2017). Nesse sentido, o CR identificou quatro grandes áreas nas quais existem problemas que devem ser solucionados pela ONU e seus Estados Membros com vistas a reduzir as fatalidades de peacekeepers; a partir dessas grandes áreas, o relatório elencou 18 recomendaçóes às Naçóes Unidas, aos países contribuintes e demais entes envolvidos com as operaçôes de paz com vistas a resolver a questão das fatalidades de peacekeepers.

\section{Mudança de Mentalidade}

A primeira questáo levantada pelo relatório é a necessidade de uma mudança de mentalidade (changing mindset) entre todos os entes envolvidos com OPs; estes devem reconhecer os riscos desses novos ambientes e estar dispostos a tomar medidas para dirimir as ameaças aos membros das missóes. De acordo com o relatório, haveria uma 'Síndrome do Capítulo VI" na ONU que condiciona as OPs a um modelo tradicional que não é adequado a áreas hostis. Como resultado, essa 'síndrome' levaria à adoção de uma postura defensiva que ofereceria ao agressor a vantagem do ataque à missão. Nesse sentido, o uso intensivo da força seria o meio para reduzir as ameaça à segurança dos peacekeepers (CRUZ; PHILLIPS; CUSIMANO, 2017).

O relatório indica a necessidade de adaptação dos atores envolvidos em operaçóes de paz aos ambientes hostis nos quais se encontram (Ponto 1). A ideia é que os comandantes das tropas no terreno assim como os países contribuintes de tropas (TCCs) e de policias (PCCs) ofereçam treinamento, equipamento e atitude condizentes ao ambiente hostil que ameaça a vida dos peacekeepers. O relatório aponta que essa adaptação também deve atingir questōes doutrinárias, como uma reavaliação da Doutrina Capstone (CRUZ; PHILLIPS; CUSIMANO, 2017). 
Ao promover a adaptação aos novos ambientes nos quais as OPs são empregadas, o CR oferece duas outras recomendaçóes no âmbito das mentalidades. De acordo com o relatório, a vulnerabilidade dos peacekeepers está relacionada com a falta de uma postura proativa da OPs frente as ameaças. Nesse sentido, os autores do relatório advogam a favor do uso da força como meio de reduzir as ameaças; essa força seria proativa, isto é, através de patrulhas, ações noturnas, snipers e da realização de ações contra grupos violentos (Ponto 2) (CRUZ; PHILLIPS; CUSIMANO, 2017).

Por extensão, o CR aponta que os comandantes das missões devem visar sempre a segurança de suas tropas (Ponto 3). Assim, o relatório reforça a necessidade do cumprimento das regras e regulaçâo de segurança das bases, por exemplo. Interessante apontar que, segundo o relatório, missóes compostas por tropas de muitas nacionalidades tendem a enfraquecer a segurança do todo, pois cada contingente se preocuparia apenas consigo mesmo; nesse sentido, o CR defende um comando central forte e coeso para sanar essa dificuldade (CRUZ; PHILLIPS; CUSIMANO, 2017).

\section{Aprimoramento das Capacidades Materiais}

A segunda grande área é o aprimoramento das capacidades materiais das missóes (improving capacity). Nesse âmbito, o relatório alega que os peacekeepers atualmente não estariam equipados, qualificados e treinados para atuarem nos ambientes onde são desdobrados. $\mathrm{O} \mathrm{CR}$ também revela a necessidade de que as tropas mais bem equipadas e treinadas estejam mais presentes nas OPs e dispostas a contribuir inteiramente para o bom funcionamento da missão (CRUZ; PHILLIPS; CUSIMANO, 2017). Pode-se afirmar que é nessa grande área que o $\mathrm{CR}$ oferece o maior número de recomendações para as Naçôes Unidas. Assim, primeiramente, o CR defende a necessidade de que cada missão tenha sua própria Statement of Unit Requeriment (SUR), ou seja, a ONU e os demais componentes das missóes não podem padronizar todos as aspectos operacionais de todas as OPs; o indicado é que os requerimentos operacionais sejam específicos de cada missão, adaptados as necessidades dos ambientes nos quais são empregadas (Ponto 4) (CRUZ; PHILLIPS; CUSIMANO, 2017).

A questão da preparaçáo das tropas revela ser fundamental para que os peacekeepers não sejam ameaçados; evidencia-se a necessidade de que as tropas estejam equipadas e preparadas para atuar em ambientes hostis no quais ainda há algum grau de beligerância. O CR indica a necessidade de verificação prévia das tropas, antes do desdobramento, cabendo ao DPKO garantir que tropas que não alcançarem determinado grau de performance não sejam desdobradas (Ponto 7). Essa mesma ideia vale para o envio de unidades policiais para missóes de paz (Ponto 8). Revelando a importância da preparaçâo e treinamento dos peacekeepers, o Cruz Report defende a necessidade de treinamento durante a OP, como forma de adequar as tropas às condições e ameaças específicas do terreno; para isso, o relatório sugere a realização de exercícios mensais e que as rotaçóes das tropas não impliquem em perda de conhecimento das condiçóes desses ambientes (Ponto 9) (CRUZ; PHILLIPS; CUSIMANO, 2017).

O Cruz Report se debruça também sobre as ameaças próprias que esses ambientes hostis oferecem as OPs. Por isso, procura oferecer saídas para a redução das ameaças provenientes de emboscadas a comboios e patrulhas (Ponto 10), de dispositivos explosivos improvisados (IED) (Ponto 11) e a redução de ataques às bases e campos das missões (Ponto 12). Com vistas a dirimir essas ameaças, o CR aponta a necessidade de treinamentos de capacitação das tropas contra essas ameaças, a utilização de tecnologias que previnam os ataques como o uso de drones, equipamento antibombas, melhoria da 
proteçấo das bases (cercas, portóes, grades) e adoção de uma postura proativa como a formação de Unidades de Reação Rápida para casos de ataques às bases, por exemplo. O CR também aponta a necessidade da formaçáo de um setor de inteligência para, ao promover o compartilhamento de informações através da integração entre os diferentes níveis da missão, melhorar a capacidade da missão de atuar tanto no nível tático quando humano (Ponto 13) (CRUZ; PHILLIPS; CUSIMANO, 2017).

Por fim, ainda na questão das capacidades materiais, o CR salienta a necessidade da formação de uma estrutura médica adequada que possa atender, em tempo satisfatório, as necessidades da operação; assim, faz-se necessário unidades médicas móveis, treinamento em primeiro-socorros e equipamento médico adequado (Ponto 14) (CRUZ; PHILLIPS; CUSIMANO, 2017, p. 29-30).

\section{Cálculo de Ameaças e a Presença das Naçôes Unidas em Terrenos Hostis}

A terceira grande área refere-se à tomada de consciência das ameaças que esses ambientes hostis representam para missão (achieving a threat-sensitive mission footprint), ou seja, defende a ideia de que a ação da ONU deveria estar condicionada a parâmetros de segurança dos membros da operação. Em outras palavras, a ONU não poderia objetivar estar presente de forma intensa em todo um território ainda em conflito se isso ameaça a segurança de seu pessoal; nesse sentido, o cálculo de ameaças deve orientar a presença das Naçóes Unidas no terreno das missões de paz (CRUZ; PHILLIPS; CUSIMANO, 2017).

$\mathrm{O} C R$ aponta que uma presença intensa da missão em um território necessita da ação de longos comboios e viagens para regióes distantes, o que aumenta o grau de ameaça e a vulnerabilidade da missão que está atuando em território hostil. É preciso, nesse sentido, reavaliar a necessidade dessa presen- ça tão intensa quando não há capacidade material para garantir a segurança dos peacekeepers e quando a regiấo ainda está sob um grau de beligerância que impede a ação segura da missão no local (Ponto 15) (CRUZ; PHILLIPS; CUSIMANO, 2017).

Nessa questão de cálculo das ameaças, é preciso que as informaçóes sobre o terreno sejam de qualidade para que possam respaldar as analises e açôes futuras das missóes de paz. Dessa forma, é possível incluir nessa seçấo acerca do cálculo de ameaças o Ponto 5 que trata da necessidade de investigação após ataques. De acordo com o Cruz Report, é preciso haver um grupo especializado que consiga extrair as informaçôes mais importantes acerca do cenário de um ataque para que a missão possa se orientar de forma satisfatória. Ainda nessa questão dos dados, vale salientar que $C R$, nos pontos 17 e 18, defende a necessidade do DPKO construir uma bases de dados completa e minuciosa acerca das fatalidades e lesóes sofridas por peacekeepers e prestadores de serviço afim de orientar o cálculo de ameaças das missões (CRUZ; PHILLIPS; CUSIMANO, 2017).

\section{Revisáo das Responsabilidades}

A quarta e última grande área identificada pelo relatório busca atribuir um maior nível de responsabilização por parte daqueles que detém poder para modificar a situação atual das OPs (enhancing accountability). De acordo com o CR, todas as instâncias de comando das operaçôes de paz - sejam os comandantes das OPs, o Departamento de Operaçôes de Paz (DPKO), os países contribuintes de tropas (TCCs) e de policiais (PCCs) - precisariam agir rapidamente pois estariam permitindo que tropas despreparadas atuassem em ambientes hostis e, consequentemente, tornando-os alvos de ações violentas. Nessa lógica, a ONU, os TCCs, PCCs seriam responsáveis pelas mortes de peacekeepers pois permitem que as tropas e policiais sejam desdobrados sem o treinamento, equipamento e 
mentalidades condizentes com as ameaças que enfrentarão no terreno. Caberia a esses entes mudar essa condição, impedindo que tropas despreparadas sejam mobilizadas, oferecendo o treinamento e equipamento necessários e, obviamente, aplicando as recomendações elencadas por esse relatório (Ponto 16) (CRUZ; PHILLIPS; CUSIMANO, 2017).

É ainda nesse sentido que se insere o Ponto 6 sobre Impunidade e Responsabilidade. O relatório afirma que as agressōes a capacetes azuis são com frequência impunes, e caberia à ONU, portanto, se certificar de que os agressores sejam levados à justiça. Por fim, a recomendação entende que caberia ao Tribunal Penal Internacional julgar esses agressores por "crimes de guerra" (CRUZ; PHILLIPS; CUSIMANO, 2017).

\section{Reações ao Cruz Report}

O Cruz Report gerou diferentes reaçôes quando de sua publicação. É possível afirmar que o ponto mais debatido e contestado do relatório seja a defesa do uso proativo da força como forma de sobrepujar os grupos que ameaçam as OPs. Williams (2018) afirma que essa constatação do CR ignora o fato dos grupos em conflito serem atores políticose, por conseguinte, sujeitos a incentivos políticos para cessarem de atacar. Além disso, afirma o autor, seria simplista imaginar que apenas uma maior capacidade militar inibiria qualquer ação contra as missóes de paz - atores mais fracos atacam atores mais fortes quando há incentivos para tal, por isso, o convencimento seria melhor que a coerção.

Como observado na seção anterior, o CR defende a adaptação das OPs aos ambientes hostis e a adoção da força como forma de dissuadir as ameaças. Contudo, essa postura mais belicista é questionada por alguns críticos que enfatizam a necessidade do uso de meios políticos como forma de se reduzir os conflitos e, consequentemente, as ameaças. Bouthellis (2018) afirma que o Cruz Report exemplifica um movimento que busca solucionar questôes de segurança com aumento do uso da força e com respostas militares; nesse sentido, o CR estaria se contrapondo a um modelo baseado em soluçôes mais abrangentes e políticas como aquelas observadas no High-Level Independent Panel on Peace Operations (HIPPO) de 2015. Hunt (2018), por sua vez, afirma que a adoção de uma nova estratégia e tática militar não pode ser a única saída das Naçôes Unidas para se resolver o problema das fatalidades e ameaças à OPs; é preciso que os conflitos nos quais a ONU se dispóe a atuar com missões de paz tenham chance de solução política; sem perspectiva de solução política não existe nível de força capaz de reduzir as ameaças.

Há ainda aqueles que defendem que essa discussão acerca da viabilidade de solução política dos conflitos nos quais as Operações de Paz são empregadas deveria ser anterior à discussão das táticas e doutrinas operacionais no terreno. Autores como Williams (2018), Bouthellis (2018) e Taylor (2018) questionam o fato do CR náo discutir o porquê de o Conselho de Segurança estar autorizando o envio de operaçôes de paz para regiôes com conflitos ativos, ou seja, onde não há paz para se manter. Caberia, portanto, ao CSNU a responsabilidade de explicar o porquê de enviar operaçóes de paz, tradicionalmente constituídas para atuarem em regiōes pacificadas, para ambientes de alto risco, colocando em perigo a vida dos membros da missão. Essa associação direta entre maior capacidade militar das OPs com uma redução quase que automática nas ameaças aos peacekeepers também é contestada por outros autores (HENKE, 2018; KHALIL, 2018a).

Um segundo grupo de críticas se atém à preocupação de que o CR estaria alargando ou até mesmo rompendo com os princípios basilares das Operaçôes de Paz - imparcialidade, consentimento, uso da força para autodefesa. Existe a percepção de 
que o uso da força afim de sobrepujar agressores da ONU romperia com o princípio de imparcialidade, transformado as operaçóes de paz em alvos legítimos dentro do conflito pois alteraria sua condiçáo dentro do Direito Internacional, trazendo mais risco de fatalidades (KHALIL, 2018a; HUNT, 2018; HOWARD, 2018; BOUTHELLIS, 2018). Nesse sentido, Bouthellis (2018) aponta para o fato de que uma ação mais coercitiva e ativa das OPs traz consigo a percepçáo, por parte dos grupos beligerantes, de que as tropas da ONU são parciais, ou seja, estão lutando a favor de determinado lado do conflito. Consequência disso seria o fato de que as tropas da ONU passariam a se tornar alvos dos grupos beligerantes, aumentando a insegurança dos peacekeepers.

Mona Ali Khalil (2018b) aponta as consequências que o uso agressivo da força tende a gerar para o status das OPs dentro do Direito Internacional. De acordo com a autora, ao atuar de forma agressiva, ou seja, atuando contra determinado grupo beligerante, as tropas das Naçóes Unidas perdem seu status de imparcialidade frente o Direito Internacional e podem ser considerados como um ator beligerante também. Essa situação, segundo Khalil, já ocorre na República Democrática do Congo onde desde 2013 a ONU passou a atacar determinados grupos rebeldes. Nessa lógica, o ataque contra peacekeepers não poderia mais ser enquadrado como crime de guerra, como havia sido considerado anteriormente. Contudo, Khalil (2018b) aponta que ao continuar aplicando sançóes contra grupos rebeldes em resposta a ataques contra peacekeepers, o Conselho de Segurança revela ainda não estar ciente dessa nova condição jurídica na qual as OPs estão inseridas. Por fim, alega a autora, que essa mudança do status das OPs tende a se modificar também em outras áreas hostis como Sudão do Sul, República Centro-Africana e Mali, onde a ação das missóes de paz tem se tornado cada vez mais agressiva (KHALIL, 2018b)
Nesse ponto, Howard (2018) argumenta que o CR aproxima as operaçóes de paz do conceito de açóes de contra insurgência. Uma ação de contra insurgência pressupóe estar ao lado do governo central utilizando a força contra determinados grupos rebeldes e beligerantes, ou seja, essas características não condizem com os princípios de imparcialidade, consentimento e uso restrito da força que fundamentam originalmente as operaçôes de paz.

Ainda em relação aos princípios das OPs, Khalil (2018c) aponta que o uso agressivo e proativo da força pode fazer com que o Estado Anfitrião retire o seu consentimento a partir do momento que considerar que esse uso da força está sendo utilizado contra suas próprias tropas ou contra seus interesses; uma vez que o consentimento é necessário para o desdobramento de uma OP, essa situação pode dificultar o bom funcionamento da missão. Por fim, sobre o uso da força, essa açáo agressiva seria um rompimento do principio de uso apenas para autodefesa e/ou para proteçâo de civis uma vez que, como proposto pelo CR, a força seria utilizada a nível tático e estratégico (KHALIL, 2018c).

Martin-Brûlé (2018) e Hunt (2018) questionam também o quanto esse uso da força afetaria a credibilidade das OPs frente a populaçáo local. Ao utilizarem o uso da força de forma proativa, as açôes dos peacekeepers se assemelhariam aos dos demais grupos beligerantes, afetando a credibilidade da missão frente a população, algo que é fundamental para o bom exercício das operaçóes de paz no terreno.

É possível observar também alguns questionamentos acerca dos dados utilizados pelo CR para fundamentar sua análise sobre as fatalidades de peacekeepers. De acordo com Martin-Brûlé (2018), ao focar apenas nas mortes provocadas por ações violentas, o relatório perde a noção do quadro geral das operaçóes no qual o número de mortes por acidentes e doenças ainda é muito elevado. Além dis- 
so, como aponta Howard (2018), ao esmiuçar esses dados de fatalidades percebe-se que grande número de fatalidades ocorreu em uma única operação, a MINUSMA no Mali; a especificidade da atuação das Naçôes Unidas nessa operação, já mencionadas acima, relativizariam a urgência em relação as fatalidades em OPs como um todo.

Contudo, nem todas as críticas são negativas ao Cruz Report. Parece ser ponto pacifico entre os comentadores que é preciso melhorar a condição do equipamento e treinamento das tropas desdobradas em ambientes de alto risco, além de se evitar que os contingentes empregados na missão possuam limites impostos à sua atuação (caveat), o que inviabiliza o bom funcionamento dos procedimentos de segurança e dos objetivos das OPs (BOUTHELLIS, 2018; GOWAN, 2018).

James Cunliffe (2018) vai ao encontro das recomendaçóes feitas pelo Cruz Report, principalmente no que tange à necessidade de treinamento das tropas mobilizadas em ambientes hostis e de maior coordenação entre os diferentes atores que gerem as OPs. Nesse último ponto, Cunliffe (2018) aponta a necessidade de Nova York estar mais conectada e ciente das necessidades que esses ambientes demandam, seja com o Conselho de Segurança fazendo mandatos menos extensos no início de missões de paz em áreas hostis, seja com a percepção de que essas áreas necessitam de maior atenção por parte do $\mathrm{DPKO}$ e do DFS (CUNLIFFE, 2018).

Em relação as críticas negativas ao $\mathrm{CR}$, Gowan (2018) sugere que esse estranhamento gerado pelas sugestões do CR resulta do fato do relatório representar o retorno dos militares em um ambiente por muito tempo dominado por atores políticos e civis; e que o CR destacaria os posicionamentos do componente militar das operaçôes, equilibrando a ação entre civis e militares no que tange o funcionamento das operaçóes de paz.
Por fim, é importante apontar como Haeri (2018), diretor de divisão dentro do DPKO, considera o Cruz Report uma parte de uma reforma mais ampla que as Operações de Paz das Naçóes Unidas estão passando. Haeri (2018) admite que as OPs estão sendo desdobradas em terrenos hostis e reconhece que o Cruz Report não se debruça sobre esse tema. Não obstante, defende o autor, o objetivo do relatório é resolver especificamente a questão das fatalidades de peacekeepers enquanto que as mudanças nas Operações de Paz continuam a ser discutidas dentro do Conselho de Segurança e na ONU. Nesse sentido, as Naçóes Unidas consideram as recomendações do relatório úteis para dirimir as ameaças e fatalidades dos peaceekeepers consideradas um problema que deve ser solucionado rapidamente.

\section{Conclusão}

Uma análise do CR carece de uma contextualização prévia. Em primeiro lugar, deve-se enfatizar que o CR segue no rastro de uma série estudos e recomendaçôes encomendados pelo Secretário-Geral da ONU desde a década de 1990 visando reformar e produzir novas diretrizes acerca das operações de paz. Com efeito, o CR difere em relação ao Relatório Brahimi $i^{4}$, ao "New Horizon" $\mathrm{e}$ ao próprio $\mathrm{HIPPO}^{6}$ - para citar os mais proeminentes - em sua ênfase sobre um problema específico, e como solucioná-lo. Isto é, para se combater o indesejado aumento do número de fatalidades de capacetes azuis recomenda o relatório o emprego ostensivo do uso da força e o abandono do modo tradicional de operaçóes de paz.

4. Relatório do Painel das Naçóes Unidas para as Operações de Paz [A/55/305] (AGNU, 2000)

5. A New Partnership Agenda: Charting a New Horizon for UN Peacekeeping (UN, 2009)

6. Report of the High-level Independent Panel on Peace Operations. Uniting our strengths for peace: politics, partnership and people [A/70/95] (UN, 2015) 
Em segundo lugar, o CR surpreendeu analistas pela linguagem direta e modo como explicita táticas ostensivas aplicadas pelos capacetes azuis como alternativas ao problema da sua vulnerabilidade, mas sobre as quais evitou-se falar por muito tempo dentro da ONU. Um dos motivos pelo incômodo gerado pelo relatório foi sua objetividade em expor contradiçóes internas ao funcionamento da organização, seus princípios e burocracias. Imparcialidade, neutralidade e autonomia, conceitos caros às missôes humanitárias foram colocados em xeque pelo CR ao questionar as possibilidades de se observar esses valores em cenários hostis como encontrados na República Centro-Africana, República Democrática do Congo ou Mali.

Em suma, o CR impóe uma pergunta básica às operaçôes de paz da ONU que possuem a proteção de civis como seu maior objetivo: como é possível promover a proteçâo humana sem colocar em risco a vida daquele que protege? E como evitar que atitudes tomadas pelos capacetes-azuis para aumentar sua proteção não aumente o grau de vulnerabilidade dos civis que devem ser protegidos?

Infelizmente, a primeira fase do projeto materializado na publicação do CR não oferece respostas a todos os dilemas de que trata o relatório. Cabem aqui duas observaçôes a esse respeito. Por um lado, algumas recomendações oferecidas pelos autores ou já foram experimentadas sem sucesso em outras ocasióes, ou foram imediatamente rechaçadas pelo Departamento de Operaçóes de Paz no momento de sua divulgaçáo. Trata-se de recomendações que sugerem mudanças profundas no modo de funcionamento da organização, sua disposição orçamentária, distribuição de competências, e regulamentação. Por outro lado, o maior desafio é a incompatibilidade entre como o relatório entende que a ONU deveria ser e como ela realmente é. A ONU é uma organização política, não militar. Isso faz a organização um reflexo da qualidade da con- vergência ou não de interesses de seus membros. Nesse sentido, a reforma do Conselho de Segurança poderia ser objeto de análise da segunda fase do referido projeto.

\section{Referências}

ASSEMBLEIA GERAL DA ONU [AGNU]. Relatório do Painel sobre as Operaçóes de Paz das Naçóes Unidas. A/55/ 305-S/2000/809. Nova Iorque: Nações Unidas, 21 ago. 2000. BOUTELLIS, A. Hostile Forces: Cruz Report Risks Distracting from Strategic Context. IPI Global Observatory, New York, 05 feb. 2018. Disponível em: <https://theglobalobservatory.org/2018/02/cruz-report-strategic-context/>. Acesso em: 24 abr. 2019.

CRUZ, A. S., PHILLIPS, W., CUSIMANO, S. Improving Security of United Nations Peacekeepers: we need to change the way we are doing business. Independent Report, [s.l.: s.n], dec. 2017. Disponível em: <https://peacekeeping.un.org/ sites/default/files/improving_security_of_united_nations_ peacekeepers_report.pdf $>$. Acesso em: 24 abr. 2019.

CUNLIFFE, J. Unprepared and Unprotected: UN peacekeepers lives must be saved. Pass Blue, New York, 9 jan. 2018. Disponível em: <https://www.passblue.com/2018/01/09/ unprepared-and-unprotected-un-peacekeepers-lives-must-be-saved/>. Acesso em: 24 abr. 2019.

GOWAN, R. Fighting Words: The Cruz Report Restores a Military Voice to Peacekeeping Debates. IPI Global Observatory, New York, 19 feb. 2018. Disponível em: <https:// theglobalobservatory.org/2018/02/fighting-words-cruz-report-restores-military-voice/>. Acesso em: 24 abr. 2019.

HAERI, D. Strengthening UN peacekeeping: placing the Santos Cruz Report in context. IPI Global Observatory, New York, 28 feb. 2018. Disponível em: <https://theglobalobservatory.org/2018/02/strengthening-peacekeeping-cruz-report-context/> Acesso em: 24 abr. 2019.

HENKE, M. E. Robust Mandates and Malicious Acts: Examining the Deadly link. IPI Global Observatory, New York, 21 feb. 2018. Disponível em: <https://theglobalobservatory. org/2018/02/mandates-malicious-acts-examining-deadly-link/> Acesso em: 24 abr. 2019.

HOWARD, L. M. Should U.N. peacekeepers launch preemptive strikes? The Cruz report seems to think so. The Washington Post, Washington DC, 16 mar. 2018. Disponível em: <https://www.almendron.com/tribuna/should-u-n-peacekeepers-launch-preemptive-strikes-the-cruz-report-seems-to-think-so/> Acesso em: 24 abr. 2019.

HUNT, C. T. Protecting Peacekeepers Requires Better Politics, Not More Force. IPI Global Observatory, New York, 14 feb. 2018. Disponível em: <https://theglobalobservatory. 
org/2018/02/protecting-peacekeepers-better-politics/> Acesso em: 24 abr. 2019.

KHALIL, M. A. The world needs robust peacekeeping not an aggressive peacekeeping. Humanitarian Law \& Policy, [s.l.], 15 may 2018c. Disponível em: <https://blogs.icrc.org/law-and-policy/2018/05/15/world-needs-robust-peacekeeping-not-aggressive-peacekeeping/> Acesso em: 24 abr. 2019.

KHALIL, M. A. When is an attack on UN peacekeepers a war crime when is it not? Pass Blue, New York, 30 nov. 2018b. Disponível em: <https://www.passblue.com/2018/11/30/ when-is-an-attack-on-un-peacekeepers-a-war-crime-and-when-is-it-not/> Acesso em: 24 abr. 2019.

KHALIL. M. A. The UN's Cruz Report on Improving Peacekeepers' Security goes too far. Pass Blue, New York, 20 may 2018a. Disponível em: <https://www.passblue. com/2018/05/20/the-uns-cruz-report-on-improving-peacekeepers-safety-goes-too-far/> Acesso em: 24 abr. 2019.

MARTIN-BRÛLÉ, S. Cruz Report: Above and Beyond Security. IPI Global Observatory, New York, 23 feb. 2018. Disponível em: <https://theglobalobservatory.org/2018/02/ cruz-report-above-beyond-security/> Acesso em: 24 abr. 2019.

TAYLOR, A. U.N. troops told to fight back, use force as peacekeeper death surge. The Washington Post, Washington DC, 23 jan. 2018. Disponível em: <https://wapo.st/2UTEum2> Acesso em: 24 abr. 2019.

UNITED NATIONS [UN], Uniting our Strengths for Peace - Politics, Partnership and People: Report of the High-Level Panel on Peace Operations. A/70/95-S/2015/446. New York: United Nations, jun. 2015. Disponível em: <https://www.refworld.org/docid/558bb0134.html>. Acesso em: 24 abr. 2019.

UNITED NATIONS [UN]. A New Partnership Agenda: charting a new horizon for UN peacekeeping. Nova York, julho de 2009. Disponível em: <https://peacekeeping.un.org/ sites/default/files/newhorizon_0.pdf >. Acesso em: 25 abr. 2019.

WILLIAMS, P.D. Cruz Report: The Politics of Force and the United Nations' Peacekeeping Trilemma. IPI Global Observatory, New York, 09 feb. 2018. Disponível em: <https:// theglobalobservatory.org/2018/02/cruz-report-peacekeeping-trilemma/> Acesso em: 24 abr. 2019. 